\title{
Aggravated Dental and Periodontal Status in Patients with Sickle Cell Disease and Its Association with Serum Ferritin
}

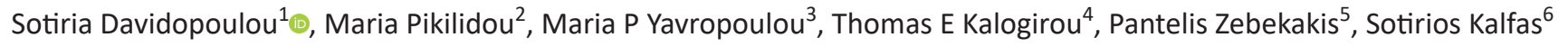

\begin{abstract}
Aim:The present study aimed to evaluate the possible consequences of sickle cell disease (SCD) on dental and periodontal health in middle-aged patients and to examine the association of certain cardiovascular parameters and serum ferritin with the dental and periodontal status.

Materials and methods: Thirty-seven patients (mean age 43.2 years old) with SCD and 30 non-SCD and otherwise healthy individuals (mean age 38.9 years old) were examined for caries experience and periodontal status in addition to cardiovascular characteristics and ferritin level in serum. Results: Compared to controls, SCD patients exhibited higher plaque and gingival bleeding scores, higher prevalence of periodontal diseases, and higher caries experience. Multiple stepwise linear regression analysis showed that caries experience was predominantly determined by the presence of SCD and the age, while major determinants of periodontitis were the ferritin levels and the male gender. The results reveal an aggravation of oral health in SCD patients regarding both caries and periodontal diseases.

Conclusion: A potential role of the increased central inflammatory response, reflected by the elevated ferritin level in serum, is suggested for the impaired periodontal health of SCD patients.

Clinical significance: Compliance with precautionary dental checks and early management of dental complications is of great importance in order to improve oral health status and prevent general health complications in SCD patients.

Keywords: Caries, Cross-sectional study, Ferritin, Periodontitis, Sickle cell disease.

The Journal of Contemporary Dental Practice (2021): 10.5005/jp-journals-10024-3189
\end{abstract}

\section{INTRODUCTION}

Sickle cell disease (SCD), an autosomal recessive inherited blood disorder, is the most prevalent hemoglobinopathy worldwide and it has been recognized as a global public health burden by the World Health Organization. ${ }^{1}$ It arises from a point mutation on the $\beta$-globin gene (HBB:c.20 A>T), which leads to the substitution of glutamic acid by valine at position $\mathrm{VI}$ of the $\beta$-globin ( $\beta 6 \mathrm{Glu}>\mathrm{Val}$ ) chain and to the subsequent formation of the abnormal hemoglobin $\mathrm{S.}^{2}$ The homozygous inheritance of the sickle hemoglobin gene (HbS) homozygous sickle cell hemoglobin genotype (HbSS) is the most severe and prevalent form of SCD, while the heterozygous inheritance heterozygous sickle cell hemoglobin (genotype HbAS) remains asymptomatic under normal conditions and is known as sickle cell trait. ${ }^{2}$

The polymerization of deoxygenated hemoglobin S plays a critical role in the acute and chronic clinical manifestations of SCD. ${ }^{2}$ SCD is characterized by dysfunctional erythrocytes that are severely deformed and have also acquired increased cell rigidity. The condition often leads to hemolytic anemia. In addition, the increased adhesiveness of the sickle cells evokes microvascular obstructions in the capillaries and small vessels. Persistent intravascular hemolysis ${ }^{3}$ combined with episodic vascular occlusion and end-organ ischemia causes sustained stress to the cardiovascular system of patients with SCD and result in chronic vasculopathy. ${ }^{4-7}$ Despite the low peripheral and central blood pressure levels, patients with SCD demonstrated increased arterial stiffness, compared to non-SCD individuals. ${ }^{5}$ As a chronic disease, SCD can lead to progressive vascular disorders, organ damage, and susceptibility to infections.

SCD is reported to associate with several pathological conditions in the oral cavity, such as delayed tooth eruption,
1,6Department of Preventive Dentistry, Periodontology and Implant Biology, Dental School, Aristotle University of Thessaloniki (AUTH), Thessaloniki, Greece

${ }^{2,5}$ Hypertension Excellence Center, First Department of Internal Medicine, AHEPA University Hospital, Aristotle University of Thessaloniki (AUTH), Thessaloniki, Greece

${ }^{3}$ Endocrinology Unit, First Department of Propaedeutic Internal Medicine, Medical School, National and Kapodistrian University of Athens, Athens, Greece

${ }^{4}$ Division of Vascular Surgery, Second Department of Surgery, General Hospital of Thessaloniki "G. Gennimatas", Aristotle University of Thessaloniki (AUTH), Thessaloniki, Greece

Correspondence Author: Sotiria Davidopoulou, Department of Preventive Dentistry, Periodontology and Implant Biology, Dental School, Aristotle University of Thessaloniki (AUTH), Thessaloniki, Greece, Phone: +30 6974642483, e-mail: sdavidop@dent.auth.gr

How to cite this article: Davidopoulou S, Pikilidou M, Yavropoulou MP, et al. Aggravated Dental and Periodontal Status in Patients with Sickle Cell Disease and Its Association with Serum Ferritin. J Contemp Dent Pract 2021;22(9):991-997.

Source of support: Nil

Conflict of interest: None

atrophy of tongue papillae, impaired dentine mineralization, periodontal diseases, and caries, ${ }^{8-17}$ but the results are inconsistent. In addition, the subjects studied are young patients with a mean age of $<35$ years and mostly children, thus leaving a knowledge gap regarding the oral health in older SCD patients.

A recent study in SCD patients revealed a positive association between the iron overload estimated by the serum transferrin

(c) The Author(s). 2021 Open Access This article is distributed under the terms of the Creative Commons Attribution 4.0 International License (https://creativecommons. org/licenses/by-nc/4.0/), which permits unrestricted use, distribution, and non-commercial reproduction in any medium, provided you give appropriate credit to the original author(s) and the source, provide a link to the Creative Commons license, and indicate if changes were made. The Creative Commons Public Domain Dedication waiver (http://creativecommons.org/publicdomain/zero/1.0/) applies to the data made available in this article, unless otherwise stated. 
saturation level and the extent and progression of periodontitis. ${ }^{18}$ Ferritin, an acute-phase reactant, is elevated in inflammation ${ }^{19}$ and associated with periodontal disease. ${ }^{20,21}$ High levels of serum ferritin were previously reported in SCD patients. ${ }^{22}$ In addition, arterial stiffness has been associated with periodontitis ${ }^{23}$ that also appears elevated in SCD patients. ${ }^{5}$

In the present study, we aimed to examine the carious and periodontal status of middle-aged SCD patients and to investigate whether vascular and metabolic parameters, such as arterial stiffness and serum ferritin levels, interrelate with SCD and the specific dental conditions.

\section{Subjects and Methods}

\section{Subjects}

A total of 37 adults with SCD were included in this cross-sectional single-center study. Thirty-year-olds and gender-matched controls were also included. The patients with SCD were recruited from consecutive patients who met the inclusion criteria ${ }^{24}$ from the pool of patients that regularly visited the Hematology Unit of the First Department of Internal Medicine in AHEPA University Hospital.

\section{Inclusion-exclusion Criteria}

Patients with SCD to be included had to be drug naïve and in a steady disease state, with no acute illness, vaso-occlusive, or acute chest syndrome episode, for at least 6 months. Patients with (i) diabetes mellitus or other endocrine diseases, (ii) arterial hypertension, (iii) known cardiovascular disease, (iv) chronic renal failure (GFR $<59.0 \mathrm{~mL} /$ minute/1.73 $\mathrm{m}^{2}$ ), (v) liver failure and/or chronic $B$ and $C$ hepatitis, and (vi) history of cancer were excluded.

As controls, 30 non-SCD and otherwise healthy individuals that had not received any medication for the last 6 months in the same range of age and body mass index (BMI), and with a similar gender distribution were recruited from the hospital staff and accompanying persons.

All study participants have answered a questionnaire regarding prior dental visits, oral hygiene practices, and diet habits. All had visited their dentists in the last year, followed a standard oral hygiene, and no extreme dietary habits were recorded.

\section{Ethical Approval}

The study conformed to the ethical guidelines of the Declaration of Helsinki and it was approved by the ethics review board of the AHEPA University Hospital, Thessaloniki, Greece. All participants gave their written informed consent. Clinical data were collected using a standardized form that included sociodemographic characteristics, medical history, current medication, and smoking habits.

\section{Methods}

\section{Metabolic Measurements and Assessment of Arterial Stiffness}

Following an overnight fast, morning blood samples were obtained from all participants. Basic biochemical assessment, including total cell blood counts, triglycerides, low-density lipoprotein, high-density lipoprotein, total cholesterol, ferrum, and ferritin were immediately measured in the serum, using standardized laboratory methods.

On the same occasion, brachial blood pressure was measured at the sitting position following a 5 -minute resting period, three times for each arm. The average of the second and third measurements on both the right and left arms was used in the analysis. Aortic pulse wave velocity (PWV) was calculated from measurements of common carotid and femoral artery waveforms, using an automatic applanation tonometry-based device (SphygmoCor Vx System, AtCor, Itasca, Illinois). PWV was calculated as the distance between recording sites measured over the surface of the body, divided by the time interval between the feet of the pressure waves. The same observer, blinded to the subject's clinical data, performed all the measurements. The point at which the central aortic pressure becomes augmented by wave reflection is recognized by a computer program, and the degree of increase is expressed as the aortic augmentation, which is quantified either in absolute term or as a percentage of aortic pulse pressure, resulting in the aortic augmentation index (Alx).

\section{Oral Assessment}

Oral examination was performed by an experienced dentist, blinded to the cases and controls with the use of a dental mirror, an artificial light source, and an appropriate probe. The oral hygiene status was determined by the plaque index (PI). The presence of plaque was recorded on six tooth surfaces (mesiolingual, mid-lingual, distal-lingual and mesiobuccal, mid-buccal and distal-buccal) on all existing teeth, without using disclosing solution. ${ }^{25}$ The number of surfaces positive for the plaque was divided by the total number of surfaces to give a percentage mean score.

The periodontal assessment included bleeding on probing (BOP), clinical attachment loss (CAL), and pocket depth (PD) measurements. The periodontal examination was performed with the use of Williams periodontal probe (Carl Martin, Solingen, Germany) and by following the instructions and criteria of the World Health Organization. ${ }^{26}$ The gingival inflammation expressed by BOP was determined at six sites on each tooth and summarized as a mean percentage value in the same manner as for PI. PD and CAL were also recorded at six sites on each tooth as described earlier. They were measured in millimeters with the periodontal probe and a vertical force of approximately $25 \mathrm{~g}$ (i.e. $0.25 \mathrm{~N}$ ).

The periodontal condition of the participants was diagnosed as proposed at the 2017 World Workshop on the Classification of Periodontal and Peri-implant Diseases and Conditions. ${ }^{27}$ Thus, as periodontally healthy were considered the participants who displayed BOP $<10 \%$, no $C A L$, and pocket depth $<3 \mathrm{~mm}$. Subjects having gingivitis exhibited BOP $>10 \%$, PD $<4 \mathrm{~mm}$, and $\mathrm{CAL}$ detectable at $<2$ teeth. For the diagnosis of periodontitis, the subjects showed BOP $>10 \%$ and interdental CAL detectable at $\geq 2$ nonadjacent teeth, or buccal or oral CAL $\geq 3 \mathrm{~mm}$ with PD $>3 \mathrm{~mm}$ detectable at $\geq 2$ teeth were diagnosed with periodontitis.

Carious lesions were detected with a standard dental explorer by applying the visual-tactile technique. The Decayed, Missing, and Filled Teeth (DMFT) index was calculated to determine the dental caries experience of each participant. ${ }^{26}$

\section{Statistical Analysis}

All data are presented as means \pm standard deviation (SD). For statistical comparisons between groups, Mann-Whitney tests were performed. The correlation between different factors was tested using Spearman's $R$ coefficient. In all hypotheses testing procedures, the observed significance levels ( $p$ value) were computed by the Monte Carlo simulation method. This approach leads to valid inferences even in cases where methodological presuppositions of the nonparametric tests are not satisfied. ${ }^{28}$

To identify determinants of DMFT and periodontitis, multiple regression analysis was conducted in the whole population, using 
the presence of disease as a dichotomous independent variable $(0=$ control, $1=S C D)$. The independent variables that were included in the models were those found to correlate with the dependent variable in the univariate analysis $(p<0.1)$. The analysis was performed with SPSS (Statistical Package for Social Sciences, IBM) v25.0 statistical package enhanced with the module Exact test. The statistical significance level of all was predetermined at $p<0.05$.

The sample size was based on a power analysis conducted prior to the study. In specific, the primary endpoint was to test whether there is a difference in the incidence of periodontitis between the SCD group and the control group. The study had $80 \%$ power to detect a difference of $35 \%$ in the incidence of periodontitis between the SCD group and the control group with $n=30$ subjects in each group for a level of significance of alpha $=0.05$.

\section{Results}

The characteristics of the participants are shown in Table 1. The mean values of age and BMI, and the gender distribution were similar for the two groups. However, differences were observed for certain vascular and metabolic characteristics between the two groups. Compared to the controls, SCD patients had significantly lower: (a) cholesterol, (b) brachial systolic and diastolic blood pressures, and (c) central diastolic blood pressure. The Alx of SCD group was significantly higher than the one found in the controls.

Significantly, higher values for all dental and periodontal indices were recorded in the SCD patients than the controls. The prevalence of periodontal diseases was also significantly $(p=0.001)$ higher in the SCD group (Fig. 1). Periodontally healthy was 35\% of the subjects in SCD group and $80 \%$ in the controls. Similarly, 38 and $27 \%$ of SCD patients had gingivitis and periodontitis, respectively. The corresponding proportion for the controls was $10 \%$ for each condition, i.e., a three- to fourfold lower prevalence of the diseases in this group.

Regarding the caries experience, the SCD patients demonstrated significantly higher DMFT index $(p=0.003)$, which was mainly reflected by the increased caries activity (DT, $p=0.005$ ), and the high tooth loss due to caries (MT, $p=0.003$ ). No difference existed for the filling teeth (FT) score. When the total number of teeth present in the mouth was compared between the two groups, the difference was significant at $p=0.002$.

The correlations of the oral conditions with the metabolic and vascular parameters in controls and SCD patients are shown in Tables 2 and 3, respectively. Apart from the expected significant correlation with age, DMFT also correlated with PWV and central systolic blood pressure in SCD patients. In the controls, DMFT significantly correlated with the Alx, BMI, and triglycerides. In the SCD group, periodontitis correlated with the central SBP, PWV, age, ferritin, and ferrum levels. Likewise, periodontitis correlated with the ferritin level of the controls.

The results of the multiple regression analyses are shown in Table 4. DMFT was predominantly determined by the presence of SCD and age after having adjusted for central systolic blood pressure, PWV, and ferritin that were found to correlate significantly with DMFT in the univariate analysis. Similarly, logistic regression analysis using periodontitis as a dependent variable showed the ferritin levels and the male gender as major determinants of periodontitis for all participants.

\section{Discussion}

The present study gives new insight into the oral status of elder SCD patients since most previous studies investigated much younger
Table 1: Characteristics of the participants of the study

\begin{tabular}{|c|c|c|c|}
\hline Characteristics & $\begin{array}{l}S C D \text { group } \\
(N=37)\end{array}$ & $\begin{array}{l}\text { Control group } \\
(N=30)\end{array}$ & $p$ value \\
\hline \multicolumn{4}{|l|}{ (A) General } \\
\hline Age (year) & $43.2 \pm 9.6$ & $38.9 \pm 2.0$ & ns \\
\hline $\begin{array}{l}\text { Body mass index } \\
\left(\mathrm{kg} / \mathrm{m}^{2}\right)\end{array}$ & $23.7 \pm 3.2$ & $24.3 \pm 3.1$ & ns \\
\hline Males (\%) & $60 \%$ & $46.7 \%$ & ns \\
\hline Smoking habit (\%) & $27.8 \%$ & $16.7 \%$ & ns \\
\hline \multicolumn{4}{|l|}{ (B) Metabolic } \\
\hline $\begin{array}{l}\text { Total cholesterol } \\
(\mathrm{mg} / \mathrm{dL})\end{array}$ & $145.7 \pm 44.7$ & $197.4 \pm 35.1$ & $<0.001$ \\
\hline Triglycerides (mg/dL) & $110.0 \pm 61.6$ & $84.6 \pm 39.8$ & 0.038 \\
\hline $\begin{array}{l}\text { Low-density } \\
\text { lipoprotein (mg/dL) }\end{array}$ & $99384.0 \pm 37.03$ & $128.67 \pm 31.42$ & $<0.001$ \\
\hline $\begin{array}{l}\text { High-density } \\
\text { lipoprotein (mg/dL) }\end{array}$ & $40.0 \pm 10.3$ & $52.0 \pm 13.8$ & $<0.001$ \\
\hline $\begin{array}{l}\text { Ferritin }(\mathrm{ng} / \mathrm{mL}) \\
\text { (normal range: } \\
50.0-170.0)\end{array}$ & $157.8(1439.9)$ & $31.9(175.8)$ & $<0.001$ \\
\hline $\begin{array}{l}\text { Ferrum }(\mathrm{mg} / \mathrm{dL} \text { ) } \\
\text { (normal range: } \\
10.0-291.0)\end{array}$ & $98.8 \pm 47.7$ & $95.9 \pm 44.0$ & ns \\
\hline \multicolumn{4}{|l|}{ (C) Vascular } \\
\hline $\begin{array}{l}\text { Brachial systolic } \\
\text { blood pressure } \\
(\mathrm{mm} \mathrm{Hg})\end{array}$ & $113.6 \pm 12.8$ & $122.5 \pm 11.6$ & 0.007 \\
\hline $\begin{array}{l}\text { Brachial diastolic } \\
\text { blood pressure } \\
(\mathrm{mm} \mathrm{Hg})\end{array}$ & $69.4 \pm 8.7$ & $81.1 \pm 9.1$ & $<0.001$ \\
\hline $\begin{array}{l}\text { Central systolic } \\
\text { blood pressure } \\
(\mathrm{mm} \mathrm{Hg})\end{array}$ & $105.3 \pm 12.7$ & $109.1 \pm 10.2$ & ns \\
\hline $\begin{array}{l}\text { Central diastolic } \\
\text { blood pressure } \\
(\mathrm{mm} \mathrm{Hg})\end{array}$ & $70.0 \pm 8.4$ & $79.4 \pm 9.8$ & $<0.001$ \\
\hline Heart rate (bpm) & $76.0 \pm 10.5$ & $74.7 \pm 9.9$ & ns \\
\hline $\begin{array}{l}\text { Aortic augmentation } \\
\text { index (\%) }\end{array}$ & $23.8 \pm 10.1$ & $11.3 \pm 10.9$ & $<0.001$ \\
\hline $\begin{array}{l}\text { Pulse wave velocity } \\
\text { (m/second) (normal } \\
\text { range }<10 \mathrm{~m} / \text { second) }\end{array}$ & $7.1 \pm 1.2$ & $7.2 \pm 0.8$ & ns \\
\hline \multicolumn{4}{|l|}{ (D) Oral } \\
\hline Plaque index & $60(95)$ & $20(95)$ & 0.002 \\
\hline $\begin{array}{l}\text { Bleeding on probing } \\
\text { index }\end{array}$ & $50(95)$ & $20(95)$ & 0.004 \\
\hline DMFT index & $11(25)$ & $6(22)$ & 0.003 \\
\hline $\begin{array}{l}\text { DT (decayed teeth) } \\
\text { index }\end{array}$ & $1(12)$ & $0(2)$ & 0.005 \\
\hline $\begin{array}{l}\text { MT (missing teeth) } \\
\text { index }\end{array}$ & $2(25)$ & $0(19)$ & 0.003 \\
\hline $\begin{array}{l}\text { FT (filling teeth) } \\
\text { index }\end{array}$ & $7(21)$ & $5(16)$ & ns \\
\hline $\begin{array}{l}\text { Total number of } \\
\text { teeth }\end{array}$ & $28(27)$ & $30(16)$ & 0.002 \\
\hline
\end{tabular}

Statistically significant differences between SCD and control groups are indicated for each characteristic. Parametric data are presented as means $\pm \mathrm{SD}$ and nonparametric as median (range); ns, nonsignificant difference 


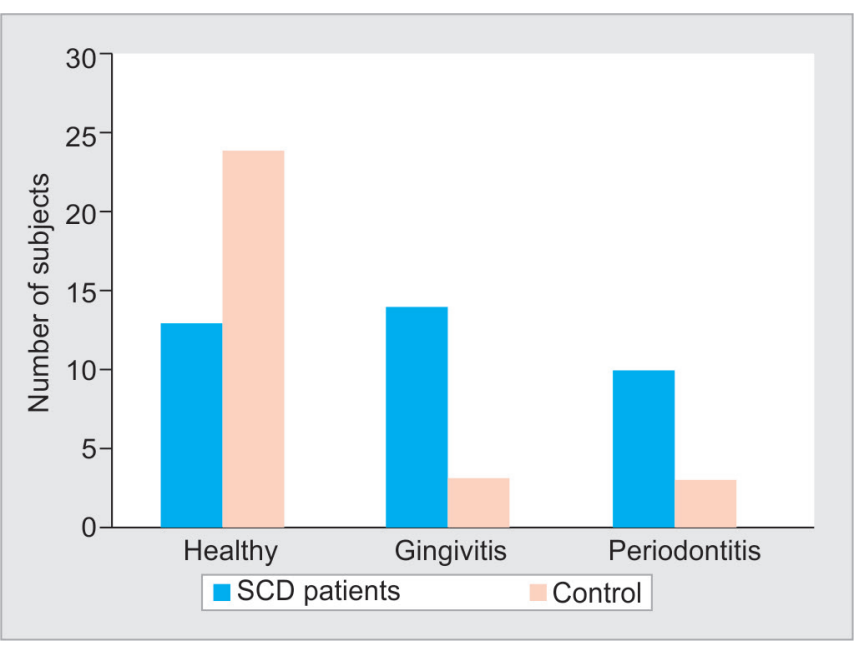

Fig. 1: Numbers of participants in each group exhibiting periodontal health, gingivitis, or periodontitis

Table 2: Simple correlations of DMFT and periodontitis with vascular and metabolic parameters in the control group

\begin{tabular}{|c|c|c|c|c|}
\hline & \multicolumn{2}{|c|}{$D M F T$} & \multicolumn{2}{|c|}{ Periodontitis } \\
\hline & $r$ & pvalue & $r$ & $p$ value \\
\hline Heart rate (bpm) & 0.097 & ns & 0.070 & ns \\
\hline $\begin{array}{l}\text { Central systolic blood pressure } \\
(\mathrm{mm} \mathrm{Hg})\end{array}$ & 0.240 & ns & 0.017 & ns \\
\hline $\begin{array}{l}\text { Central diastolic blood } \\
\text { pressure }(\mathrm{mm} \mathrm{Hg})\end{array}$ & 0.324 & ns & -0.008 & ns \\
\hline Aortic augmentation index (\%) & 0.419 & 0.021 & 0.231 & ns \\
\hline $\begin{array}{l}\text { Pulse wave velocity (m/s) } \\
\text { (normal range }<10 \mathrm{~m} / \mathrm{second} \text { ) }\end{array}$ & 0.203 & ns & 0.268 & ns \\
\hline Age (year) & 0.719 & $<0.001$ & 0.328 & ns \\
\hline Body mass index $\left(\mathrm{kg} / \mathrm{m}^{2}\right)$ & 0.464 & 0.010 & 0.262 & ns \\
\hline Total cholesterol (mg/dL) & 0.346 & ns & 0.081 & ns \\
\hline Triglycerides (mg/dL) & 0.463 & 0.010 & 0.324 & ns \\
\hline $\begin{array}{l}\text { High-density lipoprotein } \\
(\mathrm{mg} / \mathrm{dL})\end{array}$ & -0.177 & ns & -0.270 & ns \\
\hline $\begin{array}{l}\text { Low-density lipoprotein } \\
\text { (mg/dL) }\end{array}$ & 0.312 & ns & 0.057 & ns \\
\hline $\begin{array}{l}\text { Ferritin }(\mathrm{ng} / \mathrm{mL}) \text { (normal range: } \\
50.0-170.0)\end{array}$ & 0.102 & ns & 0.390 & 0.033 \\
\hline $\begin{array}{l}\text { Ferrum }(\mathrm{mg} / \mathrm{dL} \text { ) (normal range: } \\
10.0-291.0)\end{array}$ & 0.009 & ns & 0.167 & ns \\
\hline Plaque index & 0.305 & ns & 0.590 & 0.001 \\
\hline Bleeding on probing index & 0.407 & 0.026 & 0.613 & $<0.001$ \\
\hline DMFT & & & 0.426 & 0.019 \\
\hline
\end{tabular}

ns, nonsignificant

subjects. The present results reveal an aggravation of dental and periodontal health in adult SCD patients (mean age of $>40$ years) compared to healthy subjects, as also observed in previous studies in children and adolescents ${ }^{29}$ and younger adults. ${ }^{9,14,30,31}$ While the increased occurrence of gingival inflammation is in agreement with earlier findings, ${ }^{8,14,15}$ the higher prevalence of periodontitis demonstrated in this group of middle-aged adults with SCD is a novel observation. This significant finding confirms some earlier
Table 3: Simple correlations of DMFT and periodontitis with vascular and metabolic parameters in the SCD patient group

\begin{tabular}{|c|c|c|c|c|}
\hline & \multicolumn{2}{|c|}{ DMFT } & \multicolumn{2}{|c|}{ Periodontitis } \\
\hline & $r$ & $p$ value & $r$ & $p$ value \\
\hline Heart rate (bpm) & -0.089 & ns & 0.178 & ns \\
\hline $\begin{array}{l}\text { Central systolic blood pressure } \\
(\mathrm{mm} \mathrm{Hg})\end{array}$ & 0.416 & 0.011 & 0.356 & 0.031 \\
\hline $\begin{array}{l}\text { Central diastolic blood } \\
\text { pressure }(\mathrm{mm} \mathrm{Hg})\end{array}$ & 0.254 & ns & 0.097 & ns \\
\hline Aortic augmentation index (\%) & -0.009 & ns & 0.106 & ns \\
\hline $\begin{array}{l}\text { Pulse wave velocity }(\mathrm{m} / \mathrm{s} \text { ) } \\
\text { (normal range }<10 \mathrm{~m} / \mathrm{second} \text { ) }\end{array}$ & 0.354 & 0.032 & 0.332 & 0.044 \\
\hline Age (year) & 0.533 & 0.001 & 0.435 & 0.007 \\
\hline Body mass index $\left(\mathrm{kg} / \mathrm{m}^{2}\right)$ & 0.032 & ns & -0.065 & ns \\
\hline Total cholesterol (mg/dL) & 0.132 & ns & 0.057 & ns \\
\hline Triglycerides (mg/dL) & 0.193 & ns & -0.098 & ns \\
\hline $\begin{array}{l}\text { High-density lipoprotein } \\
\text { (mg/dL) }\end{array}$ & -0.311 & ns & -0.013 & ns \\
\hline $\begin{array}{l}\text { Low-density lipoprotein } \\
\text { (mg/dL) }\end{array}$ & 0.158 & ns & 0.012 & ns \\
\hline $\begin{array}{l}\text { Ferritin }(\mathrm{ng} / \mathrm{mL})(\text { normal } \\
\text { range: } 50.0-170.0)\end{array}$ & 0.303 & ns & 0.375 & 0.022 \\
\hline $\begin{array}{l}\text { Ferrum }(\mathrm{mg} / \mathrm{dL})(\text { normal } \\
\text { range: } 10.0-291.0)\end{array}$ & 0.181 & ns & 0.325 & 0.049 \\
\hline Plaque index & 0.455 & 0.005 & 0.489 & 0.002 \\
\hline Bleeding on probing index & 0.409 & 0.012 & 0.650 & $<0.001$ \\
\hline DMFT & & & 0.353 & 0.032 \\
\hline
\end{tabular}

ns, nonsignificant

Table 4: Regression analysis assessing the effect of sickle cell anemia on periodontitis and caries experience (DMFT)

Logistic regression analysis assessing the effect of sickle cell anemia on periodontitis

\begin{tabular}{llc}
\hline Independent variables & Odds ratio $(95 \% \mathrm{Cl})$ & p value \\
\hline Ferritin & $1.005(1.001-1.009)$ & 0.009 \\
Gender (male) & $7.479(1.328-42.015)$ & 0.023 \\
\hline
\end{tabular}

Significant $(p<0.05)$ correlations of periodontitis with the understudy variables were used in the model. Adjustment for subject group, age, and high-density lipoprotein, which were excluded from the model

Linear regression analysis assessing the effect of sickle cell anemia on DMFT

\begin{tabular}{lcl}
\hline Independent variables & $\beta$-coefficient & $p$ value \\
\hline Age (year) & 0.557 & $<0.001$ \\
Sickle cell (yes) & 0.220 & $<0.028$ \\
\hline
\end{tabular}

Significant $(p<0.05)$ correlations of DMFT with the understudy variables were used in the model. Adjustment for subject group, aortic augmentation index, ferritin, triglycerides, and phosphates

indications of periodontal health impairment in SCD patients..$^{8,16}$ Nevertheless, most previous studies reported no difference in periodontitis prevalence or severity, ${ }_{10-14}$ which may depend on the younger age of the populations examined, as more time is probably required for a chronic disease, such as SCD and comorbidities to affect the periodontal condition.

Another novel finding is the increased DMFT and decayed teeth (DT) scores of these SCD patients. Although a recent 
meta-analysis ${ }^{17}$ of studies in both children/adolescents and adults established no such differences, previous findings in children ${ }^{29}$ and adults ${ }^{8,9,31}$ support our results. Possibly, the age of the participants may explain the discrepancies in the caries incidence reported, as suggested previously for periodontitis too. Interestingly, some authors ${ }^{30,31}$ suggested that low-income SCD patients may be at increased risk for dental caries and they are less likely to receive restorative treatment. In general, the association of caries with the socioeconomic status is well known. ${ }^{32}$ However, it appears, from the aforementioned studies that SCD further worsens the caries status in the low-income patients. Some authors ${ }^{30}$ expressed a dentistcentered hypothesis as a possible explanation for the aggravated oral conditions of SCD subjects. According to the hypothesis, dentists may be more reluctant to provide treatment due to fear of postoperative complications in SCD patients. Psychosocial factors were also suggested to possibly influence the oral health conditions of minorities with SCD. ${ }^{30}$ Collectively and irrespective of the underlying reasons, the data support the aspect of considering SCD subjects as high-risk patients from a cariologic point of view.

A few studies have examined the relation between oral health and arterial stiffness or central hemodynamics, but no study exists for SCD patients. In patients with type II diabetes, periodontitis correlated with both arterial stiffness and central blood pressure. ${ }^{33}$ In a national US survey, periodontal inflammation was associated with raised blood pressure, ${ }^{34}$ while in patients with refractory hypertension, blood pressure and left ventricular mass were ameliorated after nonsurgical treatment of periodontitis. ${ }^{35} \mathrm{Also}$, in patients with a history of myocardial infarction, both central and peripheral blood pressures correlated with periodontal disease. ${ }^{36}$ Along this line is our finding of the positive correlation between periodontitis or DMFT and central systolic blood pressure in SCD subjects. As a matter of fact, it appears paradoxical that SCD patients have low blood pressure while their vascular stiffness is increased, this observation also being reported previously. ${ }^{5}$ Obviously, there are unknown mechanisms that counterbalance the effect of stiffness on the blood pressure. In spite of the lower blood pressure, the trend of the positive correlation between blood pressure and periodontitis, as observed in other patient groups, seems valid for SCD patients too.

Arterial stiffness has been attributed as a key component in the development of cardiovascular disease, and as it can be detected early before the occurrence of clinical signs of atherosclerosis, it acts as a marker and a predisposing factor for cardiovascular disease..$^{37,38}$ A meta-analysis of epidemiological studies demonstrated an association between periodontitis and altered arterial stiffness, ${ }^{23}$ and in addition, a recent meta-analysis concluded that patients with severe periodontitis have higher PWV compared to patients with nonsevere periodontitis. ${ }^{39}$ Our results indicate a similar association in SCD patients. Besides the increased arterial stiffness of the patients, as also shown previously, ${ }^{5}$ arterial stiffness correlated with periodontitis in this group. Chronic systemic inflammation has been advocated as the possible explanatory mechanism; however, the exact mechanism remains to be clarified, as most studies are observational and do not support a causative relation. ${ }^{40}$

Despite the significant correlations found between DMFT and PWV or central systolic blood pressure, adjustment for confounders blunted the relationship and revealed the presence of SCD and the age as the major determinants of DMFT. Although there are previous data $^{29}$ regarding lower buffer capacity of saliva in children and adolescents with SCD than normal controls, the exact mechanisms underlying the DMFT and SCD association are yet unclear. Some authors ${ }^{9}$ found other major determinants of DMFT, such as the male gender and the smoking, but not SCD. However, the discrepancies between our and the previous results may be due to differences in the methodology and the study design.

Similarly, periodontitis correlated initially with arterial stiffness and central systolic blood pressure, but regression analysis revealed ferritin and male gender as its major determinants, while SCD and smoking were excluded from the model. Again, discrepant findings were previously reported ${ }^{9}$ that might be attributed to methodological differences as with the case of caries annotated previously.

As mentioned, ferritin was presently found to be a significant determinant of periodontitis. This is an interesting and biologically plausible outcome from the point of periodontal pathogenesis. The finding is in accordance with the correlation between the high saturation level in serum transferrin and the greater extent or the rapid progression of periodontitis recently reported for SCD patients. ${ }^{18}$ Ferritin has been shown to decrease to control serum levels after periodontal treatment. ${ }^{20,21}$ After adjustment for confounders, a positive and significant correlation was also observed between serum ferritin levels and the number of sites with pocket depth $\geq 6 \mathrm{~mm} .{ }^{21}$ Further, an association between deep pockets and serum ferritin levels measured at baseline was revealed by regression analysis. ${ }^{21}$ Recently, apoferritin (the iron-free ferritin) was shown to induce the production of IL- 6 and IL-8 in human gingival tissue from periodontitis patients. ${ }^{41}$ Taken together, these findings may indicate a possible role of ferritin in triggering periodontal inflammation through cytokine induction in SCD patients.

Oral health issues are of major importance, especially for patients with such a complex disease, and often result in SCD patients arriving in hospital emergency departments with dental complications. Having a dental infection complicated by a sickle cell crisis significantly increases the likelihood of hospital admission among adult SCD patients. ${ }^{42}$ Compliance with precautionary dental checks and early management of dental complications is often neglected as patients with SCD focus all their energy on maintaining their general health due to the serious blood disorder. ${ }^{43}$ More precautionary measures and dental hygiene should be advised by physicians to take care of this delicate patient population.

\section{Conclusion}

In conclusion, this study reveals an aggravation of the dental and periodontal status in SCD patients, which manifests as increased tooth loss, increased caries activity, and increased prevalence of periodontal diseases. A potential role of the central inflammatory response, revealed by the elevation of serum ferritin, in periodontal inflammation is suggested for this patient group. Arterial stiffness and central systolic blood pressure correlated with both DMFT and periodontitis; however, SCD was found to be the major determinant of the former and the overall inflammation for the latter. There is a clear need for further studies to clarify the mechanisms of impaired oral health in subjects with SCD.

\section{Clinical Significance}

Compliance with precautionary dental checks and early management of dental complications is of great importance in order to improve oral health status and prevent general health complications in SCD patients. 


\section{OrCID}

Sotiria Davidopoulou (1) https://orcid.org/0000-0002-3436-3606

\section{ACKnOWLedgments}

The authors would like to thank Eftichia Kessopoulou, Despoina Pantelidou, and Panagiota Chalkia, for their help in the collection of data and taking care of study patients.

\section{References}

1. Modell B, Darlison M. Global epidemiology of haemoglobin disorders and derived service indicators. Bull World Health Organ 2008;86(6):480-487. DOI: 10.2471/blt.06.036673.

2. Frenette PS, Atweh GF. Sickle cell disease: old discoveries, new concepts, and future promise. J Clin Invest 2007;117(4):850-858. DOI: 10.1172/JCI30920.

3. Pinto VM, Balocco $M$, Quintino S, et al. Sickle cell disease: a review for the internist. Intern Emerg Med 2019;14(7):1051-1064. DOI: 10.1007/ s11739-019-02160-x.

4. Ter Maaten JC, Serné EH, Bakker SJ, et al. Effects of insulin on glucose uptake and leg blood flow in patients with sickle cell disease and normal subjects. Metabolism 2001;50(4):387-392. DOI: 10.1053/ meta.2001.21681.

5. Pikilidou M, Yavropoulou M, Antoniou M, et al. Arterial stiffness and peripheral and central blood pressure in patients with sickle cell disease. J Clin Hypertens (Greenwich) 2015;17(9):726-731. DOI: 10.1111/ jch. 12572.

6. Gladwin MT. Cardiovascular complications and risk of death in sickle-cell disease. Lancet 2006;387(10037):2565-2574. DOI: 10.1016/ S0140-6736(16)00647-4.

7. Liem RI, Chan C, Vu TT, et al. Association among sickle cell trait, fitness, and cardiovascular risk factors in CARDIA. Blood 2017;129(6):723-728. DOI: 10.1182/blood-2016-07-727719.

8. Kalbassi S, Younesi MR, Asgary V. Comparative evaluation of oral and dento-maxillofacial manifestation of patients with sickle cell diseases and beta thalassemia major. Hematology 2018;23(6):373-378. DOI: 10.1080/10245332.2017.1404219.

9. Passos CP, Santos PR, Aguiar MC, et al. Sickle cell disease does not predispose to caries or periodontal disease. Spec Care Dentist 2012;32(2):55-60. DOI: 10.1111/j.1754-4505.2012.00235.x.

10. Arowojolu MO, Savage KO, Aken'ova YA. Periodontal disease in homozygous HBSS adolescent Nigerians. Afr J Med Med Sci 1996;25(3):261-264. PMID: 10457802.

11. Arowojolu MO. Periodontal probing depths of adolescent sickle cell anaemic (SCA) Nigerians. J Periodontal Res 1999;34(1):62-64. DOI: 10.1111/j.1600-0765.1999.tb02223.x.

12. Arowojolu MO, Savage KO. Alveolar bone patterns in sickle cell anemia and non-sickle cell anemia adolescent Nigerians: a comparative study. J Periodontol 1997;68(3):225-228. DOI: 10.1902/ jop.1997.68.3.225.

13. Crawford JM. Periodontal disease in sickle cell disease subjects. J Periodontol 1988;59(3):164-169. DOI: 10.1902/jop.1988.59.3.164.

14. Guzeldemir E, Toygar HU, Boga C, et al. Dental and periodontal health status of subjects with sickle cell disease. J Dent Sci 2011;6(4):227-234. DOI: 10.1016/j.jds.2011.09.008.

15. Mahmoud MO, Ghandour IA, Attalla B. Association between sickle cell anaemia and periodontal diseases among 12- to 16-year-old Sudanese children. Oral Health Prev Dent 2013;11(4):375-381. DOI: 10.3290/j.ohpd.a30603.

16. De Carvalho HL, Thomaz EB, Alves CM, et al. Are sickle cell anaemia and sickle cell trait predictive factors for periodontal disease? A cohort study. J Periodontal Res 2016;51(5):622-629. DOI: 10.1111/jre.12342.

17. Yue $H, X u X, L i u ~ Q$, et al. Association between sickle cell disease and dental caries: a systematic review and meta-analysis. Hematology 2020;25(1):309-319. DOI: 10.1080/16078454.2020.1748927.
18. Costa SA, Moreira ARO, Costa CPS, et al. Iron overload and periodontal status in patients with sickle cell anaemia: a case series. J Clin Periodontol 2020;47(6):668-675. DOI: 10.1111/jcpe.13284.

19. Wang W, Knovich MA, Coffman LG, et al. Serum ferritin: past, present and future. Biochim Biophys Acta 2010;1800(8):760-769. DOI: 10.1016/j.bbagen.2010.03.011.

20. Guo LN, Yang YZ, Feng YZ. Serum and salivary ferritin and Hepcidin levels in patients with chronic periodontitis and type 2 diabetes mellitus. BMC Oral Health 2018;18(1):63. DOI: 10.1186/s1290 3-018-0524-4.

21. Chakraborty S, Tewari S, Sharma RK, et al. Effect of non-surgical periodontal therapy on serum ferritin levels: an Interventional Study. J Periodontol 2014;85(5):688-696. DOI: 10.1902/jop.2013.130107.

22. Yassin $M$, Soliman A, De Sanctis V, et al. Liver iron content (LIC) in adults with sickle cell disease (SCD): correlation with serum ferritin and liver enzymes concentrations in transfusion dependent (TD$\mathrm{SCD}$ ) and non-transfusion dependent (NT-SCD) patients. Mediterr J Hematol Infect Dis 2017;9(1):e2017037. DOI: 10.4084/MJHID.2017.037.

23. Schmitt $A$, Carra MC, Boutouyrie $P$, et al. Periodontitis and arterial stiffness: a systematic review and meta-analysis. J Clin Periodontol 2015;42(11):977-987. DOI: 10.1111/jcpe.12467.

24. Rees DC, Williams TN, Gladwin MT. Sickle-cell disease. Lancet 2010;376(9757):2018-2031. DOI: 10.1016/S0140-6736(10)61029-X.

25. O'Leary TJ, Drake RB, Naylor JE. The plaque control record. J Periodontol 1972;43(1):38. DOI: 10.1902/jop.1972.43.1.38.

26. Petersen PE, Baez RJ. Oral health survey: basic methods. 5th ed. WHO; Geneva, Switzerland; 2013. Available from: https://apps.who.int/iris/ handle/10665/97035.

27. Tonetti MS, Greenwell H, Kornman KS. Staging and grading of periodontitis: framework and proposal of a new classification and case definition. J Periodontol 2018;89(Suppl. 1):S159-S172. DOI: 10.1002/JPER.18-0006.

28. Mehta CR, Patel NR, Senchaudhuri P. Efficient Monte Carlo methods for conditional logistic regression. J Am Stat Assoc 2000;95(449): 99-108. DOI: 10.2307/2669530.

29. Brandão CF, Oliveira VMB, Santos ARRM, et al. Association between sickle cell disease and the oral health condition of children and adolescents. BMC Oral Health 2018;18:169. DOI: 10.1186/s1290 3-018-0629-9.

30. Laurence B, George D, Woods D, et al. The association between sickle cell disease and dental caries in African Americans. Spec Care Dentist 2006;26(3):95-100. DOI: 10.1111/j.1754-4505.2006.tb01430.x.

31. Laurence B, Woods D, George D, et al. Self-perceived loss of control and untreated dental decay in African American adults with and without sickle cell disease. J Health Care Poor Underserved 2006;17(3):641-651. DOI: 10.1353/hpu.2006.0107.

32. Costa SM, Martins CC, Bonfim Mde L, et al. A systematic review of socioeconomic indicators and dental caries in adults. Int J Environ Res Public Health 2012;9(10):3540-3574. DOI: 10.3390/ijerph9103540.

33. Franek E, Napora M, Blach A, et al. Blood pressure and left ventricular mass in subjects with type 2 diabetes and gingivitis or chronic periodontitis. J Clin Periodontol 2010;37(10):875-880. DOI: 10.1111/j.1600-051X.2010.01613.x.

34. Tsakos G, Sabbah W, Hingorani AD, et al. Is periodontal inflammation associated with raised blood pressure? Evidence from a National US survey. J Hypertens 2010;28(12):2386-2393. DOI: 10.1097/ HJH.0b013e32833e0fe1.

35. Vidal F, Cordovil I, Figueredo CM, et al. Non-surgical periodontal treatment reduces cardiovascular risk in refractory hypertensive patients: a pilot study. J Clin Periodontol 2013;40(7):681-687. DOI: 10.1111/jcpe.12110.

36. Łysek R, Jankowski P, Polak M, et al. Association between central and peripheral blood pressure and periodontal disease in patients with a history of myocardial infarction. Pol Arch Med Wewn 2016;126 (1-2):41-47. DOI: 10.20452/pamw.3265.

37. Ben-Shlomo Y, Spears M, Boustred C, et al. Aortic pulse wave velocity improves cardiovascular event prediction: an individual 
participant meta-analysis of prospective observational data from 17,635 subjects. J Am Coll Cardiol 2014;63(7):636-646. DOI: 10.1016/ j.jacc.2013.09.063.

38. Laurent S, Cockcroft J, Van Bortel L, et al. Expert consensus document on arterial stiffness: methodological issues and clinical applications. Eur Heart J 2006;27(21):2588-2605. DOI: 10.1093/eurheartj/ ehl254.

39. Darnaud C, Courtet A, Schmitt A, et al. Association between periodontitis and pulse wave velocity: a systematic review and meta-analysis. Clin Oral Investig 2021;25(2):393-405. DOI: 10.1007/ s00784-020-03718-2.

40. Lockhart PB, Bolger AF, Papapanou PN, et al. Periodontal disease and atherosclerotic vascular disease: does the evidence support an independent association?: a scientific statement from the American
Heart Association. Circulation 2012;125(20):2520-2544. DOI: 10.1161/ CIR.0b013e31825719f3.

41. Huang $W, Z$ han $Y$, Zheng $Y$, et al. Up-regulated ferritin in periodontitis promotes inflammatory cytokine expression in human periodontal ligament cells through transferrin receptor via ERK/P38 MAPK pathways. Clin Sci (Lond) 2019;133(1):135-148. DOI: 10.1042/ CS20180679.

42. Laurence B, Haywood C Jr, Lanzkron S. Dental infections increase the likelihood of hospital admissions among adult patients with sickle cell disease. Community Dent Health 2013;30(3):168-172. PMID: 24151791.

43. Mulimani $P$, Ballas $S K, A$ bas $A B$, et al. Treatment of dental complications in sickle cell disease. Cochrane Database Syst Rev 2016;4:CD011633. DOI: 10.1002/14651858.CD011633.pub2. 